\title{
Discovery in medicine
}

\author{
Arthur C Kennedy
}

To list and describe actual discoveries would be a monumental task; rather, I propose to look at the various ways in which discoveries are made, when they are made, what kind of person makes them, what can be done to facilitate the process, and, finally, what factors determine how discoveries are implemented into clinical practice. I will concentrate particularly on the past five or six decades, in which the pace of discovery has been remarkable.

Initially, I would like to spend a few moments on the nature and circumstances of the discovery by William Harvey that "the movement of the blood is constantly in a circle and is brought about by the beat of the heart." Although it was a profoundly important discovery, in truth it is an essentially simple observation, simple in the sense that it is something that can now readily be taught to anyone with the barest rudiments of biological knowledge - a concept that the most junior medical students have little difficulty in grasping, a truth so simple that now one wonders why it took so long to be described. But it is important to remember that around the year 1600 medical thought and teaching had been dominated-indeed, petrified-for centuries by the teaching of Galen. As Voltaire was to observe later on the risk of challenging authority, "it is dangerous to be right in matters on which the established authorities are wrong." By the time Harvey arrived in Padua to study medicine in 1600 more enlightened anatomical views than those of Galen were beginning to have credence and these provided important preliminary steps for Harvey's work. He had the supreme good fortune to be the right man in the right place at the right time. Discovery is itself one of the bases for further discovery. We stand on the shoulders of those who have gone before and Harvey, with his lively and questioning mind, was particularly

BMf 1991;303:1569-72 well endowed to take full advantage of the situation. He was prepared to question by careful and meticulous work the received wisdom of the day. "I propose to learn and to teach anatomy not from books but from dissection, not from the position of philosophers but from the fabric of nature" and with a mixture of observation, reasoning, hypothesis, and experiment was able to publish in 1626 his monumental work on the circulation of the blood.

In my view the most important of all the factors that influence discovery is the possession of a lively and questioning mind and a way of thinking, and indeed a whole attitude, that does not accept the received wisdom or dogma of the day. It is often said that only $50 \%$ of what we teach our medical students will still be accepted as correct by the time they reach the end of their professional life; the trouble, of course, is that we and they do not know which $50 \%$.

So to be around at the right time and to have a lively and questioning mind are two very important requirements for discovery. What determines whether someone will have a questioning mind-the ability so cogently expressed by Claude Bernard as "seeing what everybody has seen, and thinking what nobody has thought"? Intellect has much to do with it, but it is certainly not the only component. There are intelligent bigots and there are men full of erudition who discover nothing new; in contrast, there are many non-intellectual individuals with remarkable clarity and independence of thought and purpose. A questioning mind is undoubtedly the central attribute of all who have made major discoveries. Yet it is important to realise that even those who have questioning minds and who because of their personal efforts make major advances in knowledge can also have closed sections of their minds, where they will not permit that there could be any other way than the way they think. If we are honest with ourselves it is extraordinarily difficult to be open minded and receptive to all ideas, especially those coming from a rival camp. On reading a recent biography of Einstein, one of the most original mathematical thinkers of all time, I was fascinated to learn from letters that he wrote how petty and jealous he could be of other advances in mathematics made by rivals while at the same time he was creating dazzling new concepts in mathematical thought and understanding. Tolerance, which has been defined as a sneaking suspicion that the other person may be right, is not a constant companion of the original thinker.

The chances of the individual who is blessed with a lively and questioning mind and who has the good fortune to be around at the right time for making a significant discovery are further enhanced if he or she is working in the right environment. We are all aware of the importance of having a critical mass of intellectual activity and thought around us and to be working in a well found department with good equipment and adequate resources. This, of course, is the fundamental basis and raison d'être of the research aspects of academic medicine and even more so of research units such as those funded by the Medical Research Council and comparable organisations, and it is indeed sad that the financial support of such groups has been progressively reduced in recent years. Developments in,
Sir Fames Black was awarded the 1988 Nobel prize for medicine for his pioneering work on drugs. to treat ulcers and high blood pressure 
for example, pharmacology, virology, and molecular biology are occurring at a particularly rapid rate and all require highly professional research to follow through the ideas and discoveries generated by the most gifted researchers. In pharmacology, where most developments in the past occurred by chance or serendipity, the discovery of selective receptor blocking drugs is a splendidly successful instance of step by step programmed research based on cool deductive reasoning. Analysis of the shape of dose-response curves led to the hypothesis that there must be receptor sites for hormones and drugs in the body, and when the presence of these was confirmed and the receptors localised, studied, identified, and understood the vast resources of the pharmaceutical laboratories were able to elaborate specific or selective blocking drugs, opening up glittering new therapeutic horizons. Perhaps no one has made a greater contribution to these advances than Sir James Black with his discovery of $\mathbf{H}_{2}$ antagonists, bringing an enormous contribution to peptic ulcer management, and his discovery of $\beta$ blocker drugs, with their contribution to the management of hypertension and angina. The story is far from finished and it is virtually certain that we will see further major therapeutic advances from further identification of such products.

In virology, a race developed between researchers in Paris and Washington as to who would first identify the viral agent responsible for AIDS and delineate its characteristics. The pace of the research was intense, with publications tumbling out one after the other in an astonishingly short time considering the complexity of the task. Gallo and his group in America published in a January 1985 issue of Nature an article describing the complete nucleotide sequence of the AIDS virus. Much of the article would be quite incomprehensible to the great majority of practising doctors. Such research work is certainly not a product of the single individual: it is heavily dependent on the resources of extremely well funded laboratories - in this instance, several extremely well funded laboratories. The paper

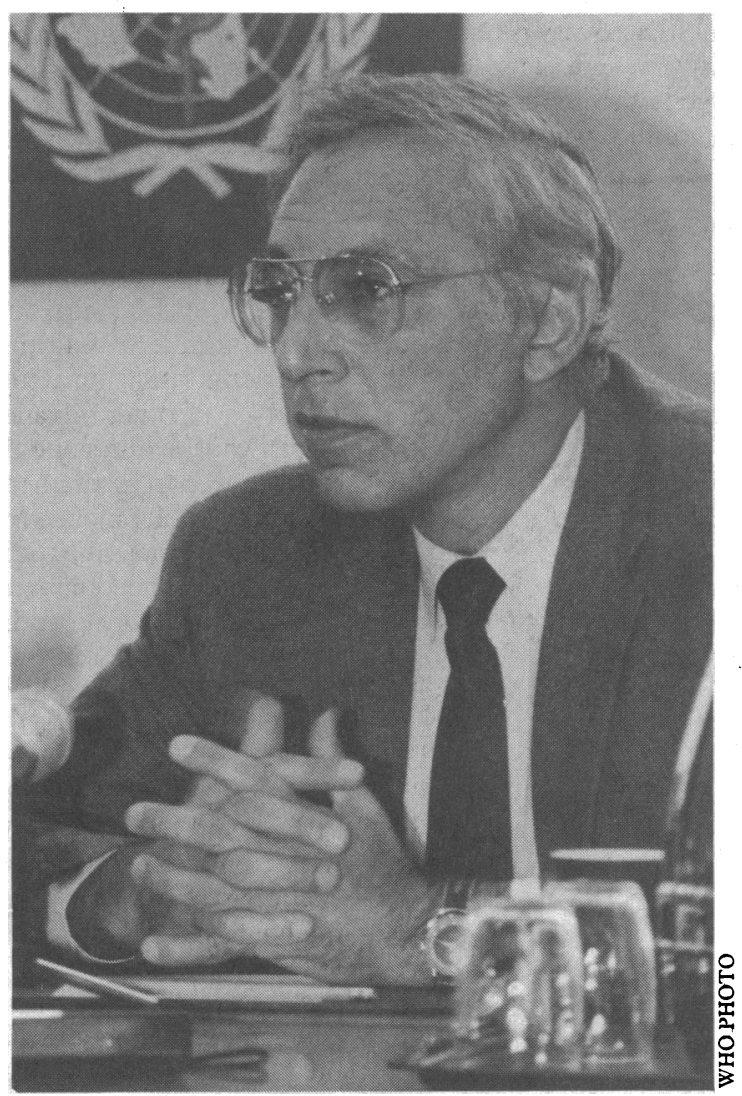

Dr Robert Gallo led American research on HIV by Gallo and his group had 19 named authors and made generous acknowledgment to the important help derived from many other individuals.

The situation is similar in molecular biology and clinical genetics, where there has been an explosion of knowledge. Teams of trained researchers continue to probe towards the complete mapping of the human genome, with the realisation of total understanding of the complete genetic material carried by an individual $\stackrel{C}{?}$ Sir David Weatherall has recently emphasised that any clinician wishing to be actively involved in such? research would require full time laboratory training in molecular biology.

We must, however, accept that not all programmed research is successful. We have to admit that sometimes we get very little benefit and a very disappointings return from programmed research that has been quite heavily. financed as a follow up to what seemed tobe very promising initial studies, and we all knoww that academic departments and research institutes gơ through fallow periods when nothing seems to comes. right - when Murphy's law (if anything can go wrong it will) prevails. Indeed, if we could programme alfw our research, and fund it adequately, and know than the results were going to be fruitful there would probably be nothing left to discover by now. As it is wehave to accept that there are still many brick walls.

\section{Factors that enhance the possibility of discovery}

To enhance the possibility of a discovery there is firstly, the glorious opportunity of developing or acquiring a new tool, a key to open a door in the brick

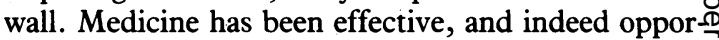
tunistic, in borrowing ideas and techniques from other sciences, and we must do everything possible to main tain and enhance cross fertilisation between scientific disciplines. A clear example is the development ofo ultrasonography, pioneered by Ian Donald following his acquaintance with radar in the Royal Air Force ando his experience of depth sounding techniques as a sailor Diagnostic ultrasonography is now in widespread use as a most valuable non-invasive technique in almos $\overrightarrow{5}$ every branch of clinical practice, and it has been followed by other equally remarkable advances in imaging, based on scientific developments on the periphery of medicine. Borrowing from other scientifies disciplines has been of enormous importance to advancement in clinical practice. It is extremelyo important for doctors to have a broadly based training so that they can maintain at least a glimmering of understanding and contact with other scientific disci plines and can realise the medical potential of developo ments and advances in such disciplines.

Another possibility is the chance observation. f doubt if there can be any more dramatic than that of Fleming, who in his classic paper of 1929 on the antibacterial action of cultures of a penicilliunt observed that on culture plates which had been setw aside on a laboratory bench "it was noticed thato around a large colony of a contaminating mould theo staphylococcus colonies became transparent and were् obviously undergoing lysis." Chain and Florey subse? quently showed that the antibacterial properties of theo mould described by Fleming were due to penicillin and a new therapeutic era was established. As a variant om the chance observation initiating a vast discovery it is o $\vec{D}$ interest also to look at the discovery of interferono Isaacs and Lindenmann were investigating why it is that one virus growing in the tissues of an animal or ifo cells cultured in the laboratory can prevent another virus growing there, even though the viruses diffe antigenically and may belong to different biological groups. During a laboratory experiment to study the entry of the virus they noted a quite unexpected result 


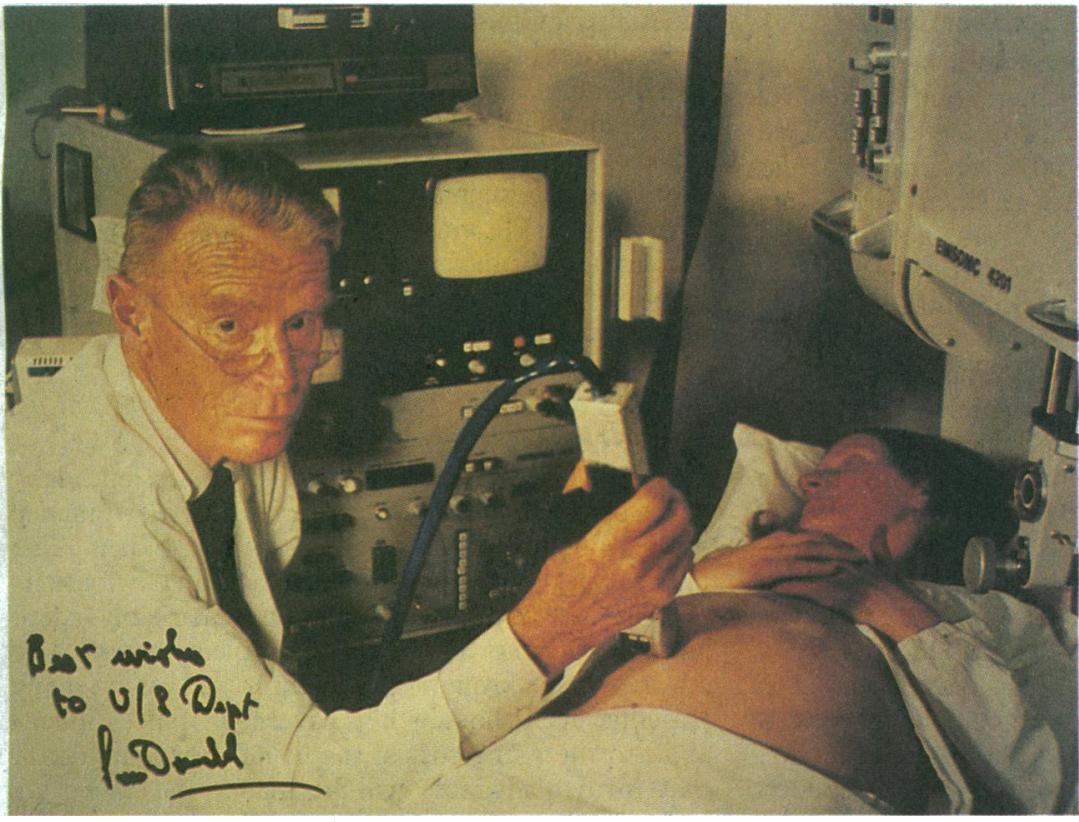

Three generations-Professor Ian Donald, who developed ultrasonography, scanning his daughter and unborn grandchild. Photograph courtesy of Mrs Alix Donald and Dr Fames Willocks

and in consequence of this were able to show that cells exposed to what they termed "interfering" virus released a protein which, when added to normal cells, made them resistant to virus infection. The discovery of interferon was, I think, a classic example of serendipity, once described in a light hearted fashion as "looking for a needle in a haystack and finding the farmer's daughter."

Many of the initial discoveries in clinical medicine were, of course, the result of gifted clinicians making clinical observations. How much is left for the humble clinician of present times to discover what has not been described before? The answer is that astute clinical observations can still result in a major discovery. Consider the observation by McBride, a consultant obstetrician in Australia, of the increased incidence of multiple severe congenital abnormalities in babies delivered of women who had received thalidomide during pregnancy. Before the drug was withdrawn, however, an estimated 10000 deformed children had been born.

Another extremely important scientific form of observation, epidemiological study, can often result in the discovery of an association between a disease and what has gone before. Bradford Hill and Doll showed this in a particularly striking way in their clear cut demonstration of the unequivocal relation between cigarette smoking and cancer of the lung. This was modern epidemiology at its best.

There is thus no single basis for discovery. Of the many components, a lively and inquiring mind which throws up ideas, being around at the right time, and being in the right environment to enable quick exploitation of even the glimmerings of a potential discovery are particularly important, I have also emphasised the importance of borrowing from other disciplines, of chance observations, serendipity, clinical observation, and epidemiology. Researchers should be aware of these many bases of discovery and pursue them as vigorously as they can. We should remember the words of James Elroy Flecker (from Hassan v.ii): "We are the pilgrims, master; we shall go always a little further." The fortunate pilgrims who make major discoveries are perhaps the ones who have the genius to remain on the right road. They are perhaps not so much lucky as, to quote Medawar, discovery prone; they are bristling with luck receptors. We should not be despondent that very few of us in the profession do make any significant discoveries. For most of us our medical and scientific life, at least as regards discoveries, is a succession of insoluble opportunities; but we can always be sustained by hope.

Factors determining how quickly discoveries and advancements are implemented

Relatively rarely, a brilliant piece of research enables a distressing disease to be eliminated at very low cost. A splendid example is the eradication in developed countries of Rhesus haemolytic disease of the newborn by treating the pregnant woman at risk with anti-D immunoglobulin; this resulted from the elegant research of Sir Cyril Clarke and his colleagues in Liverpool. Not many doctors have the privilege of is eradicating a disease that caused about 1000 neonatal $\vec{\circ}$ deaths a year in Britain alone. There was no hesitation $\rightarrow$ or delay in implementing such a discovery.

It is relatively simple to make available to the $\frac{\partial}{\partial}$ profession new drugs that promise therapeutic 3 advance, have passed the scrutiny of the Committee on $\dot{\omega}$ Safety of Medicines, and have an acceptably low level of side effects. Antibiotics, mood altering drugs, drugs $\infty$ for hypertension, $\mathrm{H}_{2}$ antagonists for peptic ulcer are all $\vec{V}$ examples of drugs that can in no way be held back from $\vec{v}$ general use even though they can cause increased 8 prescribing costs (these are often offset by reduced 은 need for hospitalisation). Even if the balance overall is towards increased costs it is a cost that has to be borne if the treatment is more effective.

More complex issues arise in terms of implementation, although not necessarily so in terms of concept, with those measures requiring skilled medical staff, $\mathbb{D}$ nursing staff, and the use of hospital beds. Examples $\vec{\bullet}$ are hip replacement surgery, regular dialysis for $\mathscr{G}$ chronic renal failure, cardiac surgery for advanced heart disease, and transplantation, now available for many organs. There has been undoubted eagerness and great enthusiasm on the part of the profession, and indeed the public, to have these implemented as

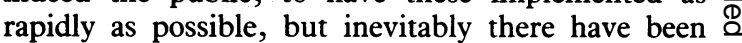
delays and I must admit to some sympathy with central $\overrightarrow{\vec{B}}$ health departments struggling to implement in full 3 such clinical advances without bottlenecks and queues developing. The NHS clearly requires better funding so that we can accommodate much more effectively worthwhile advances. In passing I would like to observe that the task of all of us is not made easier by a climate of emotional appeals based on harrowing single 3 cases directed to the population at large by the media. The diversion of scarce resource that may well result can have undesirable effects on other fronts.

It is also important to emphasise the slowness of implementation in some very important issues of $\mathcal{N}$ disease prevention which to the vast majority of the $\frac{D}{2}$ medical profession appear quite clear cut. The most obvious example is the difference between the medical $N$ profession (and indeed many of the public) and $\underset{\omega}{\mathcal{N}}$ government on the vigour of tackling the question of $O$ cigarette smoking. There is of course the freedom of the individual viewpoint, but I fear the government's attitude is determined more by the prospect of a major reduction in a $£ 6$ billion tax revenue. There are many $\tau$ other factors in the field of what we are again permitted to term public health - such as poverty, inadequate $\overparen{\cap}$ health education, poor housing, poor or inappropriate $\mathbb{D}$ diets - where a more vigorous approach would undoubtedly lead to improvement in the health of the population. Indeed it has been said that if all laboratory 응 and scientific research were halted for a few years and strenuous efforts were made to implement confirmed public health measures then enormous good would result. We must continue to press for more vigorous action on these matters 


\section{Molecular biology and genetic engineering}

Finally, I would like to dwell on a new factor of great importance in the implementation of medical discoveries-namely, the question of control and direction of the remarkable advances in molecular biology and genetic engineering of recent years. In a few years the human genome will have been mapped out and it will be known with precision where exactly the genes are that control the determination of sex, that determine the inheritance of all inherited disorders, that will predispose an individual to common acquired disorders such as hypertension, rheumatoid arthritis, diabetes, cancer, and indeed to which specific types and sites of cancer. The question is, what is to be done with all this knowledge and latent power? We already have in laboratories forms of life, bacterial and otherwise, whose genetic structure has been spliced with genetic material to enable us to manufacture products that will be of benefit in therapeutics, and there are animals whose genetic structure has been modified to produce substances of benefit in medicine. There can only be a wide basis of support for these developments, and equally there would be a wide basis of support, although not universal, for the detection in utero of the major inherited disorders that cause serious congenital abnormalities, but there is understandable concern about extension of the process to permit genetic manipulation in humans to lessen the chances of acquiring some diseases in later life or to modify or improve in other ways the genetic structure of the individual. Such issues undoubtedly require the most detailed and continuing ethical scrutiny. They cannot be determined solely by the scientists or clinicians involved in the discoveries, nor can we assume that a generally cautious and careful approach would necessarily always prevail. Comprehensive consultation and consideration and continuing discussion and debate are undoubtedly required. Whether this should be achieved by a series of commissions to tackle relatively specific issues, such as we have had already in respect of in vitro fertilisation, or whether it would be better accomplished under the aegis of a standing national body on bioethics is uncertain. The precise format is open to discussion; the need is imperative.

\section{In conclusion}

Looking back over my time in the profession, many of the advances that are now part of everyday practice were quite unforeseen when I was a student. The medical profession has made major contributions? to these advances and has been remarkably adept $\overrightarrow{\vec{\omega}}$ and forceful in promoting their implementation. The advances have brought greatly improved care to many 윽 patients, even though they have contributed, inevitably, to the rising cost of medicine. I have no doubt 0 that further advances will be made, and as we get $\sigma$ nearer and nearer a complete understanding of the molecular and genetic fabric of human life, at least in . its physical aspects, ethical considerations as to how we $\vec{G}$ are to use these new tools will become increasingly $\varnothing$ important. I am confident that if the profession 은 continues to attract lively and inquiring minds, if we $N$ are vigilant in maintaining ethical standards, if we are careful to listen to and, indeed, to seek public opinion, $\mathbb{D}$ then the next few decades will see advances just as remarkable as those that have occurred during the past decades.

\title{
Economics, health, and the economics of health
}

\author{
Charles Normand
}

Economics is the study of scarcity and choice. The tools used by economists are designed to help with the decisions about how to allocate scarce resources to infinite wants. Resources are always scarce, and choices always have to be made. The only thing that varies is how scarce are the resources, and how difficult the choices. Although spending continues to rise in real terms, the problem of scarcity and the need to choose has become a visible feature of the debate about health services in the United Kingdom.

\section{Markets, uncertainty, and insurance}

The most common method of allocation of goods and services is the market. There is something fascinating in the way that exchange in the market can make people better off as less desired goods are traded for more desired ones. In general economists argue that voluntary trading makes both parties better off - both sacrifice something of less value for something of greater value. It is therefore important to have good reasons to prevent or discourage such trading.

Markets can fail for a variety of reasons. One is the lack of information, or an asymmetry of information between the parties. For markets to work well, both parties to an exchange must be well informed about the characteristics and quality of the goods being traded.

Other types of market failure come from externalities and from public good characteristics. An externality is a good or bad effect of a good or service which falls on third parties. For example, an undesired effect of driving a car is the noise and air pollution experi- enced by other people. An example of external benefits is the effect of immunisation-my immunity to an infectious disease makes me less likely to spread the disease to others, as well as affording me protection.

Markets may also fail to work well if there is a significant degree of monopoly power. This is especi-o ally the case when producers are natural monopolies: such as those who supply gas and water. Restriction of entry into professions introduces monopoly. Although these restrictions are claimed to be (and in most cases 음 are) to protect the public from incompetent practice, N they also have the effect of restricting competition.

The great uncertainty about need for health services, and the great cost of services, makes it inevitable that people will choose to provide services through a system of insurance, whether private, social, or national (or ${ }^{\mathrm{c}}$ through general taxation). Insurance is expensive to administer, since there are many contributors and many claims. A policy question is therefore that of the cheapest way of providing this insurance cover. If incentives and efficiency are not taken into account $\frac{0}{0}$ then payment for health services from general taxation, $\overrightarrow{\mathbb{D}}$ as in Canada, Sweden, and Britain, involves the lowest $\frac{}{\oplus}$ expenditure on raising the funds.

Insurance works best when all parties are well informed about the risks and the risks and outcomes 8 are well defined. It is therefore not surprising thato insurance does not work perfectly in the area of healtho⿳亠二口 and social care. Apparently similar individuals might in fact represent very different risks. This can lead to incomplete markets, with some people failing to find insurance. ' There is enough evidence that, left to itself, 